\title{
Compensatory changes in mammary development and function after hemimastectomy in lactating goats
}

\author{
C. H. Knight \\ Hannah Research Institute, Ayr KA6 5HL, U.K.
}

\begin{abstract}
Summary. Goats were hemimastectomized during Weeks 5 or 8 of lactation. The milk yield of the remaining gland (the test gland) usually increased in a compensatory fashion after the operation, although the degree of response varied from no response to a $50 \%$ increase. The glands of those goats that responded and received no further treatment maintained an increased milk yield for the duration of the lactation. Changes in the size and composition of the gland were investigated by a combination of udder volume and biopsy in some goats. Increases in both gross size and total DNA content (DNA, a measure of cell number) were observed in all of these, although the timing of the response varied between individuals. Overall, cell population size was maintained for at least 18 weeks after hemimastectomy whereas in control (unoperated) goats DNA $_{t}$ decreased by $35 \%$ over a similar period.
\end{abstract}

\section{Introduction}

The three stages of mammary development which characterize the lactation cycle are proliferation, secretion and involution. Although most proliferation occurs during pregnancy (i.e. before secretion has started) and most involution takes place after secretion has finished, the three processes can overlap: proliferation of secretory tissue continues during early lactation and involution begins during late lactation, both concomitantly with secretion (Knight \& Peaker, 1984). The balance between proliferation and cell loss determines the size of the secretory cell population, and milk yield is ultimately determined by the number and activity of secretory cells. In some organs, such as the liver and kidney, removal of a major part of the tissue's mass stimulates proliferation in the remaining portion (see Bucher \& Malt, 1971). It has been suggested that such compensatory growth may also occur in the goat mammary gland (Linzell, 1963), although others disagree (Cowie et al., 1965). The purpose of this study was to try to resolve this difference of opinion, by determining the effects of hemimastectomy during lactation on the development and yield of the remaining gland.

Some of these data have been reported briefly elsewhere (Knight \& Peaker, 1982d).

\section{Materials and Methods}

\begin{abstract}
Animals. Saanen or predominantly Saanen cross-bred goats were used in their first lactation. They were milked twice daily at about 08:00 and 16:00 h; the time of milking and yield of each gland were recorded. Hay was available throughout the day and concentrates were fed at each milking ( $0.5 \mathrm{~kg}$ goat mix 1/day: Edinburgh School of Agriculture, Edinburgh, plus $0.75 \mathrm{~kg}$ 'Red Label'/day: BOCM Silcock). The udder volumes of the 14 experimental and 10 control animals were measured on a weekly or fortnightly basis by water displacement (Linzell, 1966). In goats with intact udders, individual gland volumes were calculated by multiplying udder volume by the fraction of the total milk yield produced by each gland, since milk yield and gland volume were significantly correlated (see 'Results', Fig. 3).

Surgical procedures. Hemimastectomies were performed $24 \mathrm{~h}$ after food withdrawal. Anaesthesia was induced with pentobarbitone sodium (Sagatal: May \& Baker, Dagenham, Essex, U.K.; $22 \mathrm{mg} / \mathrm{kg}$ i.v.) and maintained by a closedcircuit system of halothane in oxygen. With the animal dorsally recumbent, a mid-line incision was made between the two glands which were then separated by blunt dissection as far as the body wall. Vessels joining the two glands were
\end{abstract}


ligated or cauterized. A second incision was made to include the teat of the gland which was to be removed; this gland was then separated from the body wall by blunt dissection. Major blood vessels were ligated, smaller ones cauterized and the suspensory ligaments and spermatic nerve were cut. The gland was then removed, complete with its teat and some skin. The inguinal canal was closed by suturing the cut edge of the lateral suspensory ligament to the medial ligament, and the remaining gland was stitched to the body wall in layers in order to fill 'dead-space' and to appose the skin edges. Vertical mattress sutures were inserted at $5 \mathrm{~cm}$ intervals, and final closure was achieved by a continuous silk suture.

Mammary gland biopsies were taken under pentobarbitone sodium anaesthesia by the method of Knight \& Peaker (1984).

Experimental. In a preliminary study, 5 goats were hemimastectomized during Week 5 of lactation, milked for a further 7 weeks and then killed. The test gland (that which remained after hemimastectomy) was removed post mortem. The two glands were thus removed 7 weeks apart; both were weighed to obtain a gross weight then trimmed to remove skin and obvious areas of fat and reweighed (trimmed weight).

In the main experiment, 9 goats were hemimastectomized between Weeks 7 and 9 of lactation (mean $8 \cdot 2 \pm 0 \cdot 4$, s.e.): 3 of these were milked until Week 34 with no further treatment, and the other 6 were milked until Week 26 and mammary gland biopsies were taken 1, 4, 8 and 12 weeks after hemimastectomy. At the end of the experiment these biopsied animals were killed for removal of the test gland; glands removed at hemimastectomy (control gland) or post mortem (test gland) were weighed, placed on ice and a pooled tissue sample, consisting of at least ten 1-g cubes of tissue from all areas of the gland apart from the cistern, was quickly collected and weighed. A small amount of this sample $(\leqslant 0.5 \mathrm{~g})$ was placed into ice-cold Medium 199 (Flow Laboratories, Irvine, Ayrshire, U.K.) for determination of tritiated thymidine incorporation into DNA in vitro (Knight \& Peaker, 1982a). The remainder of the pooled sample was frozen in liquid nitrogen and stored at $-15^{\circ} \mathrm{C}$ until analysed for nucleic acids by a modification of the SchmidtThannhauser method (Munro \& Fleck, 1966). The rest of the gland was carefully trimmed to remove skin, all extraneous fat and the connective tissue capsule, and reweighed. The weight of the pooled sample was added to this to give the total parenchyma weight. Biopsy tissue samples were treated in the same way as pooled samples. Nucleic acid concentrations, determined in tissue samples, were multiplied by gland volume to give an estimate of the total glandular content of DNA (DNA $)$ and RNA (RNA).

Control data. A group of 10 control goats was used for comparison with the experimental groups. All were contemporaries of the experimental animals, 3 were untreated throughout lactation but the other 7 were biopsied on several occasions as part of another study (Knight \& Peaker, 1984). Biopsy data from this previous study were used for comparison with the present biopsy results.

Expression of results. Milk yield and udder volume data from all 9 animals in the hemimastectomized group were pooled until Week 25 since inter-animal variation was no greater between the biopsied and non-biopsied sub-groups than within them. The average milk yield of the left and right glands of control goats was used for comparison with the yield of the test gland of hemimastectomized animals. In the latter group, milk yield was reduced during the week of hemimastectomy but recovered during the following week (apart from one goat whose yield declined progressively after operation). Similar reductions were associated with some biopsies, in control and operated animals. When calculating group means, weighting was applied to correct transient decreases (Knight \& Peaker, 1984), but when yield was reduced for longer than 2 weeks, unweighted values were used. Analysis around the time of hemimastectomy compared the average weekly milk yield or gland volume of the test gland during the 3 weeks preceding the week of hemimastectomy with that of the 6 weeks after hemimastectomy, or the equivalent weeks of lactation in the controls.

Milk production per unit volume of glandular tissue $(\mathrm{g} / \mathrm{day} / \mathrm{ml}$ tissue) was calculated from milk yield and udder volume data, and an estimate of production per cell ( $\mathrm{g} / \mathrm{h} / \mathrm{g}$ DNA) was calculated from milk yield and DNA.

Statistical analysis. Differences between group means were analysed for statistical significance by Student's $t$ test for paired or unpaired observations, by Wilcoxon's signed rank test or by analysis of variance, as appropriate.

\section{Results}

\section{Milk yield}

Single-gland yield curves (weekly milk yield plotted against week of lactation) are shown in Figs 1 and 2. The yields shown are the average of left and right gland for control animals and the yields of the test gland for experimental animals. The yield curve for control animals demonstrated the usual pattern of an initial rise from low levels to reach a peak during Week $8(8 \cdot 5 \pm 1 \cdot 1$ weeks), followed by a more gradual decline. The yield of the experimental group was initially similar to that of the controls, but rose above it after hemimastectomy. There was a $15 \%$ increase in milk yield after hemimastectomy $(P<0.05$ by paired $t$ test, Table 1$)$ at a time when the control group's yield was constant. Peak milk yield was at $12.2 \pm 1.2$ weeks, which was significantly later than in the controls $(P<0.05, t$ test $)$. 


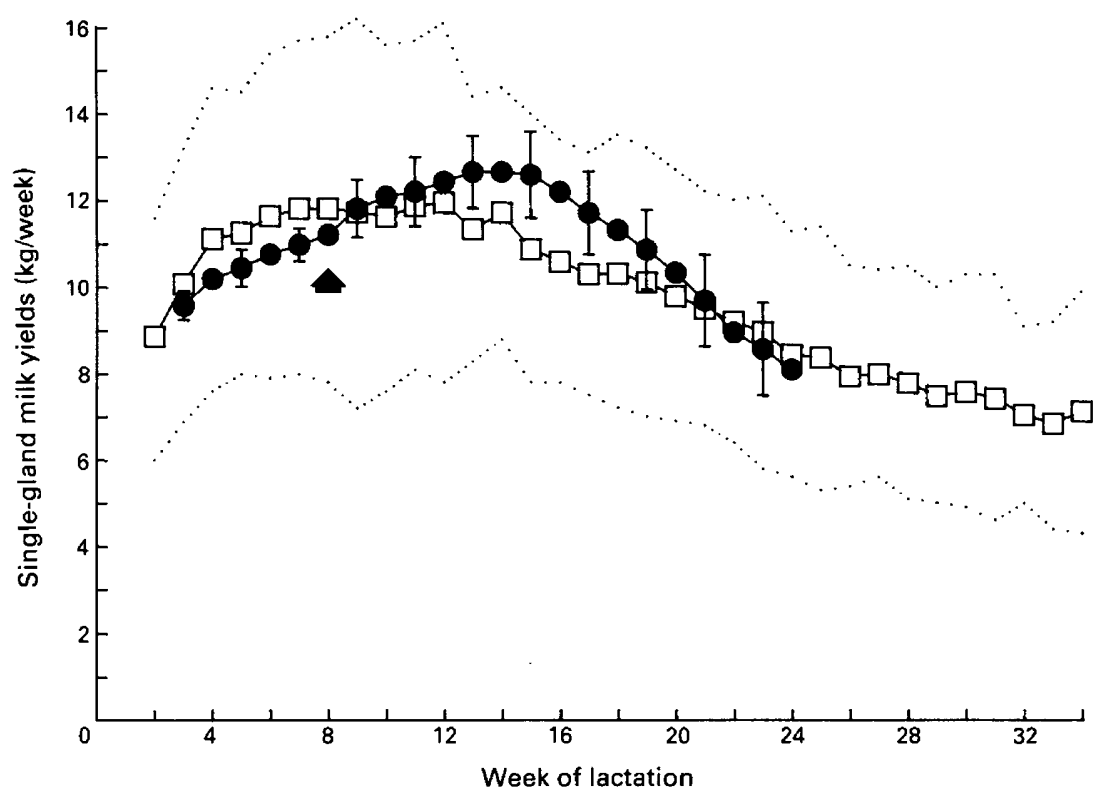

Fig. 1. Single-gland milk yield curves for groups of control goats $(\square, N=10$; mean values with $95 \%$ confidence limits indicated by dotted lines) and goats hemimastectomized in Week 8 (arrowed) $(\boldsymbol{O}, \mathrm{N}=9$; mean values with alternate s.e.m. indicated by bars; other s.e.m. are omitted for clarity).

A significant response to hemimastectomy was also observed in the preliminary study. The yield of the 5 goats hemimastectomized in Week 5 increased by $28 \%(7.65 \pm 0.98$ to $9.79 \pm 0.91 \mathrm{~kg} /$ week, $P<0.05$, paired $t$ test). During the equivalent weeks of lactation, the yield of the controls rose by $9 \%$, a significantly smaller increase $(P<0 \cdot 05, t$ test $)$.

There was considerable variation between goats in the degree of response to hemimastectomy. The yield of 2 of the 3 non-biopsied goats (Goats B9 and B14) increased markedly after hemimastectomy, rising from a value similar to that of the controls to exceed the upper $95 \%$ confidence limit of the control values for the remainder of the lactation (Fig. 2a). The third goat in this sub-group showed no response to hemimastectomy (Goat B16, Fig. 2c). Some of the biopsied goats also increased their yield markedly after hemimastectomy (e.g. Goats R9 and R29, Fig. 2b) while in others the increase was small, or in some cases yield initially increased but subsequently declined after repeated biopsies (e.g. Goat G7, Fig. 2c). Comparing the 3 weeks before hemimastectomy with the 6 weeks after hemimastectomy, 6 of the 9 hemimastectomized goats increased their yield by $10 \%$ or more (mean $24 \%$ ) and only 1 goat (Goat B16) failed to show any increase.

\section{Udder volume}

It was necessary to establish that udder volume accurately reflected actual udder size. Udder volume at or before the time of peak milk yield was significantly correlated with yield $(r=0 \cdot 84$, $P<0.001,19$ d.f., $y=61.92 x+434.8$, Fig. 3 ) in the 21 goats (14 hemimastectomized, including those used in the preliminary study, and 7 controls) for which data were available. This demonstrates the validity of using gland-yield ratios to calculate individual gland volume from udder volume before hemimastectomy. Correlations between calculated or measured gland volumes and actual gland weights (gross or trimmed) are given in Fig. 4. A significant correlation was obtained between the calculated volume of the control gland and its gross weight after removal at hemimastectomy ( $r=0.82, P<0.001,12$ d.f., $y=1.67 x-223.8$, Fig. 4a), and a similar relationship was 

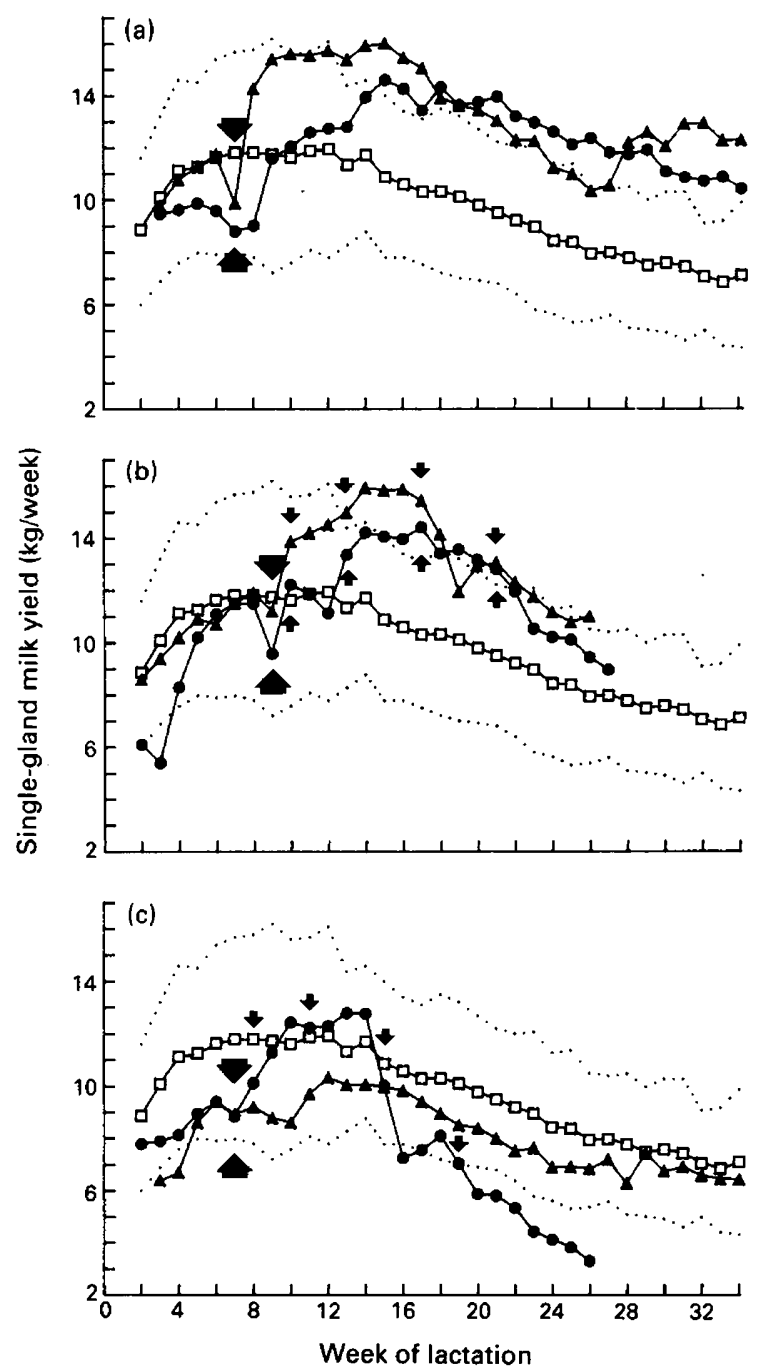

Fig. 2. Single-gland milk-yield curves for individual hemimastectomized goats. Control values as in Fig. 1. Hemimastectomy indicated by large arrow, mammary gland biopsy by small arrow: (a) $\boldsymbol{\Delta}$, Goat B14; $\bullet$, Goat B9; (b) $\boldsymbol{\Delta}$, Goat R29; •, Goat R9; (c) $\mathbf{\Delta}$, Goat B16; Goat G7.

found for the test gland ( $r=0 \cdot 76, P<0 \cdot 01,8 \mathrm{~d}$.f., data not shown). In the preliminary study, the correlation between calculated or measured volume of control or test gland and the trimmed weight of that gland was $0.92(P<0.001,8$ d.f., $y=1.62 x-136.8$, Fig. 4 b), and the equivalent correlation for the main experimental group was $0.75, P<0.01,12$ d.f. (data not shown).

In the main experimental group, the volume of the test gland increased by $25.6 \%$ after hemimastectomy $(P<0.05$, paired $t$ test $)$ at a time when the gland volume of the control animals was constant (Table 1). Similar observations were made in the preliminary study, the increases in this case being $32.4 \%$ in the hemimastectomized animals (668 \pm 66 to $884 \pm 38 \mathrm{ml}, P<0.05$, paired $t$ test) and $2.0 \%$ (non-significant) in the controls. 
Table 1. Single gland milk yield and gland size of goats during the 3 weeks before and the 6 weeks after hemimastectomy, or the equivalent weeks of lactation in control (unoperated) goats

\begin{tabular}{|c|c|c|c|c|c|c|}
\hline & \multicolumn{3}{|c|}{$\begin{array}{l}\text { Control goats } \\
(N=10)\end{array}$} & \multicolumn{3}{|c|}{$\begin{array}{l}\text { Hemimastectomized goats } \\
\qquad(\mathbf{N}=9)\end{array}$} \\
\hline & Before & After & Increase $\dagger$ & Before & After & Increase $\dagger$ \\
\hline Week of lactation & $5-7$ & $9-14$ & - & $5-7$ & $9-14$ & - \\
\hline $\begin{array}{l}\text { Single-gland milk } \\
\text { yield (kg/week) }\end{array}$ & $11.58 \pm 0.55$ & $11 \cdot 63 \pm 0 \cdot 58$ & $\begin{array}{c}0.05 \pm 0.02 \\
(0 \cdot 4 \%)\end{array}$ & $10.72 \pm 0.37$ & $12 \cdot 33 \pm 0.76^{*}$ & $\begin{array}{c}1 \cdot 61 \pm 0.60 \\
(15 \cdot 0 \%)\end{array}$ \\
\hline $\begin{array}{l}\text { Single-gland volume } \\
(\mathrm{ml})\end{array}$ & $964 \pm 67$ & $976 \pm 43$ & $\begin{array}{r}12 \pm 41 \\
(1 \cdot 2 \%)\end{array}$ & $842 \pm 73$ & $1058 \pm 55^{*}$ & $\begin{array}{r}215 \pm 64 \\
(25.6 \%)\end{array}$ \\
\hline
\end{tabular}

Values are mean \pm s.e.m.

$\dagger$ Increase between before and after hemimastectomy periods, with percentage increase in parentheses.

*Significantly different from value before hemimastectomy, $P<0.05$ (paired $t$ test).

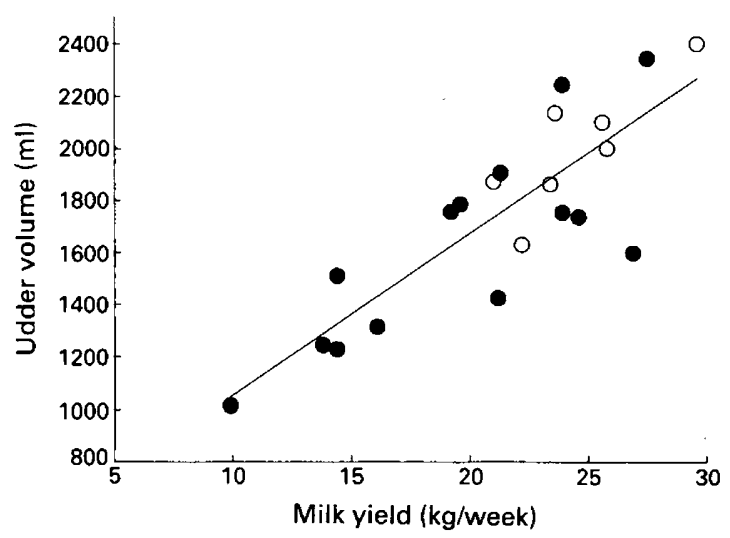

Fig. 3. Correlation between udder volume and milk yield at the time of hemimastectomy in control $(O)$ and hemimastectomized $(\odot)$ goats.

\section{Gland composition}

Data on gland composition obtained in the 6 biopsied goats are shown in Tables 2 and 3 . Analysis at the time of hemimastectomy was done on pooled tissue from the hemimastectomized (control) gland but the volume shown and calculated total contents of DNA and RNA (DNA, RNA $_{t}$ ) are those of the test gland. Analyses at 1, 4, 8 and 12 weeks after hemimastectomy were on biopsy samples of the test gland, and that at 18 weeks was on a pooled sample of the test gland obtained post mortem. Previous work has shown that analyses of biopsy samples and of pooled samples do not differ significantly (Knight \& Peaker, 1984).

Gland volume increased significantly after hemimastectomy in the 6 animals studied, reaching a maximum at 8 weeks. The concentration of DNA in the tissue ([DNA]) decreased progressively, but DNA, was maintained at a constant level throughout (Table 2). Individually, DNA increased $_{t}$ above its hemimastectomy value in each goat studied at some stage after the operation. The first increase was at Week 1 in 3 goats, at Week 4 in 2 goats and at Week 8 in one goat. Taking the maximum DNA $A_{t}$ value for each goat irrespective of when it occurred, there was an increase in DNA $_{\mathrm{t}}$ of $19 \%$ over the hemimastectomy value $(2.94 \pm 0.28$ to $3.49 \pm 0.37 \mathrm{~g}, P<0.05$, paired $t$ test). There was also a significant decline in [RNA] after hemimastectomy, but this occurred later than that in [DNA]. As a result, RNA, initially increased and at Week 4 was significantly higher 


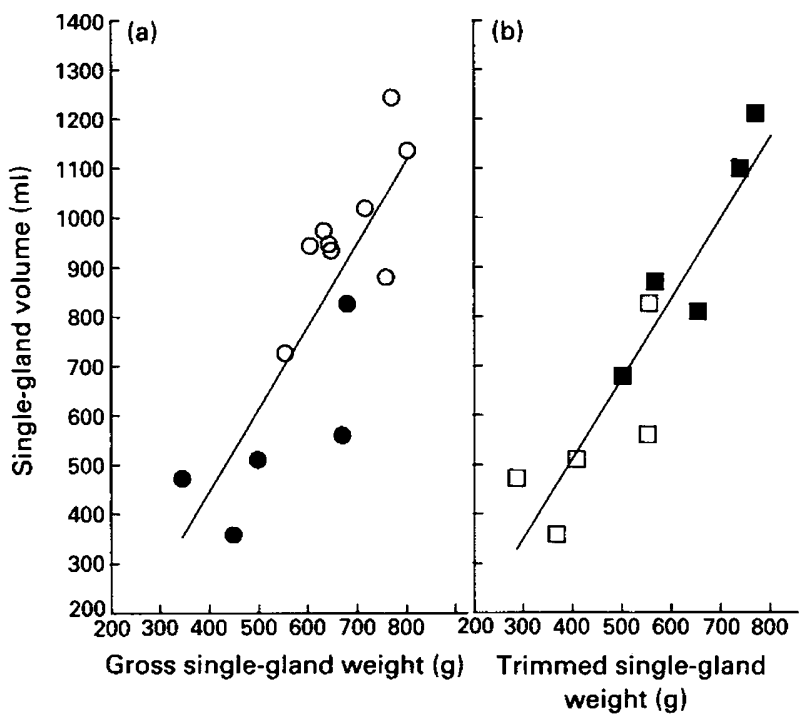

Fig. 4. Correlations between gland volume and gland weight in hemimastectomized goats. (a) Correlation between calculated volume of the control gland before hemimastectomy and its measured gross weight after removal at hemimastectomy in goats hemimastectomized in Week $5(0)$ or Week $8(O)$. Calculated volume derived from udder volume and milk yield ratios (for details, see text). (b) Correlation between the calculated or measured gland volume of the control ( $\square$ ) and test (a) glands, respectively, and their trimmed weight (gross weight minus weight of teat, skin and subcutaneous fat) after removal in goats hemimastectomized in Week 5 .

than at the time of hemimastectomy, but it declined thereafter (Table 2). The RNA/DNA ratio increased significantly at 1 and 4 weeks after hemimastectomy but then decreased such that at 12 and 18 weeks it was significantly below the hemimastectomy value.

Previously-published control composition data were available for Weeks 8 and 23 of lactation (Knight \& Peaker, 1984). In Table 3 these data (adjusted to single-gland values) are compared with the present data using the mean of results for Weeks 20 and 26 (Table 2) to approximate to Week 23. Overall, the decline in milk yield was similar in the two groups but size and compositional changes were not. Gland volume increased in the hemimastectomized animals but decreased in the controls, and although [DNA] decreased in both groups, DNA $t$ was maintained after hemimastectomy but fell significantly in the controls. The decreases in both [RNA] and RNA, were greater in the hemimastectomized group than in the controls, and consequently there was a significant fall in the RNA/DNA ratio in the hemimastectomized animals but not in the controls.

\section{Relationship between milk yield and gland size and composition}

The amount of milk produced per unit volume of mammary tissue ( $\mathrm{g} / \mathrm{day} / \mathrm{ml}$ tissue) decreased from 4 weeks after hemimastectomy onwards (Table 4). Between Weeks 8 and 23 (average of Weeks 20 and 26) it fell from $1.95 \pm 0.17$ to $1.09 \pm 0.12 \mathrm{~g} /$ day/ml tissue, an overall decrease of $0.86 \pm 0.15 \mathrm{~g} / \mathrm{day} / \mathrm{ml}$ tissue $(P<0.01$, paired $t$ test $)$. The Week 8 value was very similar in the controls $(1.89 \pm 0.08 \mathrm{~g} /$ day $/ \mathrm{ml}$ tissue $)$ but the fall to Week 23 was significantly less $(0.31 \pm 0.05 \mathrm{~g} /$ day $/ \mathrm{ml}$ tissue, $P<0.01, t$ test). The amount of milk produced per cell $(\mathrm{g} / \mathrm{h} / \mathrm{g}$ DNA) tended to increase initially after hemimastectomy but then decreased at 12 and 18 weeks after operation. Between Weeks 8 and 23 it fell from $22.83 \pm 1.77$ to $17.63 \pm 1.59 \mathrm{~g} / \mathrm{h} / \mathrm{g}$ DNA $(P<0.05$, paired $t$ 
Table 2. Size and composition of the single remaining gland at various times after hemimastectomy in goats

\begin{tabular}{|c|c|c|c|c|c|c|}
\hline \multirow{3}{*}{$\begin{array}{l}\text { Week of lactation } \\
\text { Weeks from } \\
\text { hemimastectomy }\end{array}$} & 8 & 9 & 12 & 16 & 20 & 26 \\
\hline & & & & & & \\
\hline & 0 & 1 & 4 & 8 & 12 & 18 \\
\hline \multirow[t]{2}{*}{ Gland volume $(\mathrm{ml}) \ddagger$} & $822 \cdot 7$ & $904 \cdot 2$ & $1146 \cdot 8$ & $1183 \cdot 3$ & $1147 \cdot 2$ & $923 \cdot 2$ \\
\hline & $\pm 63 \cdot 2$ & \pm 82.5 & $\pm 54 \cdot 1^{* *}$ & $54 \cdot 4^{* *}$ & $\pm 50 \cdot \mathrm{I}^{* *}$ & \pm 79.9 \\
\hline \multirow[t]{2}{*}[\mathrm{DNA}]{$(\mathrm{mg} / \mathrm{g}) \dagger$} & 3.55 & 3.09 & 2.67 & 2.49 & 2.63 & 2.81 \\
\hline & \pm 0.39 & $\pm 0.26^{*}$ & $\pm 0 \cdot 13^{*}$ & $\pm 0.36^{* *}$ & $\pm 0.34^{* *}$ & $\pm 0 \cdot 20^{*}$ \\
\hline \multirow[t]{2}{*}{ DNA (g) } & 2.94 & $2 \cdot 74$ & 2.99 & $2 \cdot 99$ & 3.04 & $2 \cdot 61$ \\
\hline & \pm 0.28 & \pm 0.24 & \pm 0.22 & \pm 0.50 & \pm 0.49 & \pm 0.36 \\
\hline \multirow[t]{2}{*}{ [RNA] $(\mathrm{mg} / \mathrm{g}) \ddagger$} & $6 \cdot 16$ & 5.88 & 5.29 & 3.64 & 3.26 & 4.01 \\
\hline & \pm 0.96 & \pm 0.85 & \pm 0.52 & $\pm 0.43^{*}$ & $\pm 0 \cdot 62^{* *}$ & $\pm 0.63^{* *}$ \\
\hline \multirow[t]{2}{*}{ RNA (g) } & 5.03 & $5 \cdot 14$ & 5.95 & $4 \cdot 38$ & $3 \cdot 82$ & 3.85 \\
\hline & \pm 0.68 & \pm 0.72 & $\pm 0.78^{*}$ & \pm 0.65 & $\pm 0.85^{*}$ & \pm 0.84 \\
\hline \multirow[t]{2}{*}{ RNA/DNA $\ddagger$} & $1 \cdot 70$ & 1.86 & 1.97 & 1.49 & $1 \cdot 19$ & 1.39 \\
\hline & $\pm 0 \cdot 10$ & $\pm 0 \cdot 14^{*}$ & $\pm 0 \cdot 14^{*}$ & \pm 0.07 & $\pm 0.09^{* *}$ & $\pm 0 \cdot 13^{*}$ \\
\hline
\end{tabular}

Values are mean \pm s.e.m. for 6 goats.

${ }^{*} P<0.05 ;{ }^{* *} P<0.01$ compared to Week-8 value (paired $t$ test).

$\dagger P<0.01 ; \ddagger P<0.001$ for effect of time after hemimastectomy (Anova).

Table 3. Single-gland size, yield and composition at the time of hemimastectomy and during late lactation in hemimastectomized and control (unoperated) goats

\begin{tabular}{|c|c|c|c|c|}
\hline & \multicolumn{2}{|c|}{$\begin{array}{l}\text { Hemimastectomized } \\
\text { goats }(\mathrm{N}=6)\end{array}$} & \multicolumn{2}{|c|}{$\begin{array}{l}\text { Control goats } \\
(\mathrm{N}=7)\end{array}$} \\
\hline & Week 8 & Week 23ł & Week 8 & Week 23 \\
\hline Milk yield (kg/week) & $10.95 \pm 0.55$ & $8.03 \pm 1.08^{*}$ & $12.74 \pm 0.64$ & $9.03 \pm 0.53^{* * *}$ \\
\hline Gland volume (ml) & $822.7 \pm 63.2$ & $1035.0 \pm 52.9^{*}$ & $972.6 \pm 53.5$ & $817.6 \pm 38.4 * * *$ \\
\hline$[\mathrm{DNA}](\mathrm{mg} / \mathrm{g})$ & $3.55 \pm 0.39$ & $2 \cdot 72 \pm 0.24^{* *}$ & $3.04 \pm 0.28$ & $2.29 \pm 0.23 \dagger$ \\
\hline DNA (g) & $2.94 \pm 0.28$ & $2.82 \pm 0.41$ & $2.92 \pm 0.26$ & $1.88 \pm 0.22^{* *}$ \\
\hline [RNA] (mg/g) & $6.16 \pm 0.96$ & $3.64 \pm 0.60^{* *}$ & $5.74 \pm 0.52$ & $5 \cdot 10 \pm 0 \cdot 30$ \\
\hline RNA (g) & $5.03 \pm 0.68$ & $3.83 \pm 0.82$ & $5.56 \pm 0.52$ & $4.21 \pm 0.39^{*}$ \\
\hline RNA/DNA & $1.70 \pm 0.10$ & $1.29 \pm 0.11^{* *}$ & $2.02 \pm 0.29$ & $2.36 \pm 0.24$ \\
\hline
\end{tabular}

Values are mean \pm s.e.m.

${ }^{*} P<0.05 ;{ }^{* *} P<0.01 ;{ }^{* * *} P<0.001$ compared with Week-8 value paired $t$ test.

$\dagger P<0.05$ compared with Week 8 value by Wilcoxon's signed rank test.

łCalculated from data in Tables 2 and 4.

Table 4. Single-gland milk yield and yield per $\mathrm{ml}$ of mammary tissue or per gram of DNA at various times after hemimastectomy in goats

\begin{tabular}{|c|c|c|c|c|c|c|}
\hline Week of lactation & 8 & 9 & 12 & 16 & 20 & 26 \\
\hline \multicolumn{7}{|l|}{ Weeks from } \\
\hline hemimastectomy & 0 & 1 & 4 & 8 & 12 & 18 \\
\hline Milk yield & $10 \cdot 95$ & $11 \cdot 50$ & $12 \cdot 23$ & $11 \cdot 85$ & $9 \cdot 53$ & 6.57 \\
\hline$(\mathrm{kg} /$ week $) \ddagger$ & \pm 0.55 & $\pm 0.74 \S$ & $\pm 1 \cdot 03$ & $\pm 1 \cdot 14$ & $\pm 1 \cdot 19$ & $\pm 1 \cdot 00^{* *}$ \\
\hline Milk yield & 1.95 & 1.90 & 1.53 & 1.43 & $1 \cdot 17$ & 1.02 \\
\hline (g/day/ml tissue $) \ddagger$ & $\pm 0 \cdot 17$ & \pm 0.25 & $\pm 0 \cdot 13$ & $\pm 0 \cdot 13^{* *}$ & $\pm 0 \cdot 12^{* *}$ & $\pm 0 \cdot 12^{* *}$ \\
\hline Milk yield & $22 \cdot 83$ & $26 \cdot 18$ & $24 \cdot 90$ & $26 \cdot 58$ & $19 \cdot 93$ & $15 \cdot 38$ \\
\hline$(\mathrm{g} / \mathrm{h} / \mathrm{g}$ DNA $) \dagger$ & \pm 1.77 & $\pm 3 \cdot 43$ & $\pm 2 \cdot 50$ & $\pm 4 \cdot 80$ & $\pm 2 \cdot 14$ & $\pm 1 \cdot 58^{*}$ \\
\hline
\end{tabular}

Values are mean \pm s.e.m. for 6 goats.

${ }^{*} P<0.05 ;{ }^{* *} P<0.01$ compared with Week 8 (paired $t$ test).

$\dagger P<0.01 ; \ddagger P<0.001$ for effect of time after hemimastectomy (Anova).

$\S P<0.05$ compared with Week 8 (Wilcoxon's signed rank test). 
test), whereas in control animals production-per-cell remained constant over the same period (Week $8,28 \cdot 10 \pm 3 \cdot 45 \mathrm{~g} / \mathrm{h} / \mathrm{g}$ DNA, not significantly different from hemimastectomized group; Week $23,30.42 \pm 2.88 \mathrm{~g} / \mathrm{h} / \mathrm{g}$ DNA, $P<0.001$ compared with hemimastectomized group, $t$ test).

\section{Discussion}

After hemimastectomy, the milk yield of the remaining gland increased in a compensatory fashion in the majority of the goats and the size of the gland increased in all of them. The variability of the yield response complicates interpretation of the results. Of the 14 hemimastectomized goats, there was no increase at all in one and the rise was less than $10 \%$ in 3 others. Nevertheless, in the short term ( 6 weeks) the increase in yield was significant even when these data were included. Between Weeks 8 and 23 of lactation the decline in milk yield was similar, overall, in the control group and in the group hemimastectomized in Week 8 , suggesting that compensatory yield increases were not maintained in the long term. This may not be so, since the yields of some of the hemimastectomized goats were markedly reduced as the result of biopsies at too-frequent intervals (see below). Indeed, those animals that responded to hemimastectomy and subsequently received no further treatment maintained an increased milk yield for the duration of the lactation.

Compensatory changes in gland size were more consistent. Gland volume increased significantly after hemimastectomy (by $32 \%$ in the preliminary study and $25 \%$ in the main experiment), and in all 6 biopsied goats the size of the mammary cell population (DNA $)$ increased at some stage after the operation. Linzell (1963) was the first to suggest that compensatory changes might follow hemimastectomy in lactating goats, but his limited data were not entirely conclusive and were questioned by others (Benson et al., 1965; Cowie et al., 1965). The present results clearly indicate that compensatory changes can occur.

The observation of mammary growth occurring during established lactation has considerable significance for our understanding of the factors governing milk yield. The normal pattern of mammary gland development is for the majority of growth to occur during pregnancy, although proliferation does continue during early lactation in rats and mice (see Cowie et al., 1980) as well as in the goat (Anderson et al., 1981; Knight \& Peaker, 1984). Changes in the number of secretory cells do therefore contribute to increased milk yield during the build-up to peak lactation, although in the goat this contribution is probably small in comparison to increases in the synthetic capacity of individual cells (Sarma \& Ray, 1984; Wilde et al., 1986). The normal course of events is for milk yield to decline gradually after peak lactation, as a result of loss of secretory cells rather than decreased activity-per-cell (Knight \& Peaker, 1984; Wilde et al., 1986). Hemimastectomy reversed this; the size of the cell population was maintained during declining lactation (between Weeks 8 and 23) but the RNA:DNA ratio, an estimate of the potential activity of individual cells, and milk yield per cell $(\mathrm{g} / \mathrm{h} / \mathrm{g}$ DNA) both decreased rather than remaining constant.

Cell population size is a consequence of the balance between cell proliferation and cell death. It could be that the absence of any decline in $\mathrm{DNA}_{1}$ was due to cell death being completely prevented by hemimastectomy, although this does not seem likely. Mammary secretory cells are extremely metabolically active, and it is almost inevitable that some would die during the 15 -week period. It is more likely that cell proliferation was increased in the hemimastectomized animals, and the fact that DNA, not only remained constant overall but actually increased at some stage in all of the goats studied does support this. The incorporation of tritiated thymidine into DNA, a measure of the rate of cell proliferation, was increased 1 and 4 weeks after hemimastectomy, but there was considerable variation between individual animals and the overall effect was not significant. Nevertheless, even a small increase in proliferation rate maintained for a long period would result in a large overall increase in the number of new cells.

There are two possible explanations for the observed decline in potential cellular activity (RNA:DNA) in the hemimastectomized goats. Firstly, newly-proliferated cells may have failed to 
differentiate completely (or at all), thus lowering the RNA:DNA ratio overall. However, if new cells did fail to differentiate then the long-term increase in yield observed in some animals must have been a consequence solely of an increase in the activity, per cell, of pre-existing tissue and evidence from other studies (Wilde et al., 1985) suggests that this is unlikely. Secondly, deleterious effects of the frequent biopsy regimen may have been responsible for the fall in RNA:DNA. In a previous study (Knight \& Peaker, 1984), 2 biopsies were taken from each gland of intact goats during the 8-week period with only transient effects on milk yield. In the present study, the additional stress of hemimastectomy followed by 4 biopsies taken from the one remaining gland in 12 weeks led to prolonged reductions in milk yield in 3 of the 6 animals. This effect may have been direct (i.e. actual tissue damage within the gland) or indirect, through deleterious effects of repeated fasting, anaesthesia and surgery on the animal's metabolism.

Investigation of the effect of thrice-daily milking of goats on mammary size and function has suggested that the observed increase in yield is achieved in the shorter term by increased activity in pre-existing tissue, and in the longer term by proliferation of new cells (Henderson et al., 1985; Wilde, et al., 1985). The same time-course of events was apparent after hemimastectomy; an initial increase in the potential activity of individual cells (RNA:DNA) was followed by a longer-term increase in the size of the cell population.

Compensatory mammary growth has been observed in other circumstances. Sheep hemimastectomized during or before pregnancy subsequently produced more than half the yield of intact controls from glands which were bigger than control half-udder size (Davis et al., 1983). A similar observation was reported for guinea-pigs by Kuosaite (1965), although others have been unable to repeat this (Linzell, 1963; Knight \& Peaker, 1981). In mice, mammary development was reduced during gestation by hemihysterectomy, presumably as a result of decreased circulating levels of placental lactogen (Knight \& Peaker, 1982b) and by short periods of fasting (Knight \& Peaker, 1982c). In both cases compensatory growth of the gland occurred during early lactation, resulting in a normal milk yield.

It is apparent from these observations that a system for monitoring gland size does exist and that this system initiates further growth when gland size decreases suddenly, falls below a 'target' size of some sort, or is incapable of meeting the functional demands (i.e. for milk) placed on it. Although the mechanisms controlling the compensatory growth are unknown, they may include systemic endocrine factors, local autocrine or paracrine factors, or a combination of more than one of these. The monitoring system may involve endocrine signals produced by the mammary gland, since it is now recognized that the gland does have an endocrine function (Maule Walker, 1984). Mammogenic hormones, or changes in the gland's ability to respond to them (e.g. through altered receptor number) may also form the compensatory growth stimulus. Local control may be mediated through increased concentrations of stimulatory growth factors (several have been found in colostrum; Brown \& Blakely, 1984; Francis et al., 1986), or decreased concentrations of growth inhibitors (e.g. a mammary chalone; Gonzalez \& Verly, 1978).

I thank Pamela Miller and Ann Docherty for expert technical assistance; I. Fleet and M. Peaker for help with surgery; and T. Hutchison and Sandra Paton for care of the goats.

\section{References}

Anderson, R.R., Harness, J.R., Snead, A.F. \& Salah, M.S. (1981) Mammary growth pattern in goats during pregnancy and lactation. J. Dairy Sci. 64, $427-432$.

Benson, G.K., Cowie, A.T., Cox, C.P., Folley, S.J. \& Hosking, Z.D. (1965) Relative efficiency of hexoestrol and progesterone as oily solutions and as crystalline suspensions in inducing mammary growth and lactation in early and late ovariectomized goats. $J$. Endocr. 31, 157-167.

Brown, K.D. \& Blakely, D.M. (1984) Partial purification and characterization of a growth factor present in goat's colostrum. Similarities with platelet-derived growth factor. Biochem. J. 219, 609-617. 
Bucher, N.L. \& Malt, R.A. (1971) Regeneration of Liver and Kidney. Little, Brown, Boston.

Cowie, A.T., Cox, C.P., Folley, S.J., Hosking, Z.D., Naito, M. \& Tindal, J.S. (1965) The effects of the duration of treatments with oestrogen and progesterone on the hormonal induction of mammary growth and lactation in the goat. $J$. Endocr. 32, 129-139.

Cowie, A.T., Forsyth, I.A. \& Hart, I.C. (1980) Hormonal Control of Lactation. Springer-Verlag, Berlin.

Davis, S.R., Day, A.M. \& Hughson, G.A. (1983) The effect of hemimastectomy on the pattern of udder development and milk production of ewes. J. Dairy Sci. 66, Suppl. 1, 106, Abstr.

Francis, G.L., Read, L.C., Ballard, F.J., Bagley, C.J. \& Upton, F.M. (1986) Purification and partial sequence analysis of insulin-like growth factor- 1 from bovine colostrum. Biochem. J. 233, 207-213.

Gonzalez, R. \& Verly, W.G. (1978) Purification of an inhibitor of DNA synthesis in mammary cells. Eur. $J$. Cancer 14, 689-697.

Henderson, A.J., Blatchford, D.R. \& Peaker, M. (1985) The effects of long-term thrice-daily milking on milk secretion in the goat: evidence for mammary growth. Q. Jl exp. Physiol. 70, 557-565.

Knight, C.H. \& Peaker, M. (1981) Lack of compensatory mammary growth following hemimastectomy in the guinea-pig. Comp. Biochem. Physiol. 70A, 427-429.

Knight, C.H. \& Peaker, M. (1982a) Mammary cell proliferation in mice during pregnancy and lactation in relation to milk yield. $Q$. Jl exp. Physiol. 67, 165-177.

Knight, C.H. \& Peaker, M. (1982b) Mammary development in mice: effects of hemihysterectomy in pregnancy and of litter size post-partum. J. Physiol., Lond. 327, 17-27.

Knight, C.H. \& Peaker M. (1982c) Effects of fasting during mid-pregnancy or early lactation on mammary development and milk yield in mice. $J$. Dairy Res. 49, 567-575.
Knight, C.H. \& Peaker, M. (1982d) Compensatory increases in milk yield after hemimastectomy in lactating goats. J. Physiol., Lond. 329, 36P, Abstr.

Knight, C.H. \& Peaker, M. (1984) Mammary development and regression during lactation in goats in relation to milk secretion. $Q$. $J l$ exp. Physiol. 69, $331-338$.

Kuosaite, B.A. (1965) Compensatory hypertrophy of the mammary gland in the guinea-pig following the removal of the right mammary gland. Bull. exp. Biol. Med. USSR 59, 317-320.

Linzell, J.L. (1963) Some effects of denervating and transplanting mammary glands. $Q$. $J l$ exp. Physiol. 48, 34-60.

Linzell, J.L. (1966) Measurement of udder volume in live goats as an index of mammary growth and function. J. Dairy Sci. 49, 307-311.

Maule Walker, F.M. (1984) Exocrine and endocrine secretions of the mammary gland: local control in ruminants. Symp. zool. Soc. Lond. 51, 171-191.

Munro, H.N. \& Fleck, A. (1966) Recent developments in the measurement of nucleic acids in biological materials. Analyst 91, 78-88.

Sarma, P.V. \& Ray, T.K. (1984) Fatty acid synthesizing capacity of mammary gland in relation to plasma hormone levels at different stages of pregnancy and lactation in goats. Ind. J. Biochem. Biophys. 21, 255-259.

Wilde, C.J., Henderson, A.J. \& Knight, C.H. (1985) Lipogenic enzyme activities in goat mammary gland: changes with stage of pregnancy and lactation and frequency of milking. Biochem. Soc. Trans. 13, $877-878$.

Wilde, C.J., Henderson, A.J. \& Knight, C.H. (1986) Metabolic adaptations in goat mammary tissue during pregnancy and lactation. J. Reprod. Fert. 76, 289-298.

Received 1 April 1986 